\title{
Utilizing Reclaimed Asphalt Pavement (RAP) Materials in New Pavements - A Review
}

\author{
Ahmad M. Abu Abdo* \\ Department of Civil \& Infrastructure Engineering, American University of Ras Al Khaimah, Ras Al Khaimah, UAE
}

\begin{abstract}
Recently, prices of asphalt pavement materials have been increasing tremendously, which led to attempts to find alternative cheap materials. In addition, more concerns are directed to reserving natural resources and reducing environmental impacts of using virgin asphalt binders, thus more attention is focused on the use of recycled materials in pavement designs. Transportation agencies worldwide are incorporating reclaimed asphalt pavement (RAP) materials in new pavement designs. RAP was used for the first time in 1973, however, with low percentages due to the lack of understanding of its effect on the performance of asphalt mixes. Currently, higher percentages (e.g. $>50 \%$ ) are being utilized to reduce costs and natural resources and make use of demolished old asphalt pavements. The main concern of combining RAP in new asphalt mixes is how it will affect the resistance of these mixes to permanent deformation (rutting), fatigue cracks, and thermal cracks, which are the main distresses that affect the performance of asphalt mixes. Many studies were conducted to evaluate the effects of RAP on asphalt mixes, and all results showed that RAP increased the stiffness of asphalt mixes, thus improving rutting resistance at high temperature. On the other hand, results were in conflict with regard to fatigue and thermal cracking. Recently, the Department of Public Works and Services at Ras Al Khaimah, UAE started adopting RAP mixes in ongoing projects (e.g. Kadra-Shawka Road) with no clear guidelines, in hope of reducing costs and that these roads would have better performance. To address the concerns of the effects of RAP and to determine the correct RAP percentage for projects in Ras Al Khaimah, this study was initiated and as a first stage a literature review was conducted and presented in this article.
\end{abstract}

Keywords: Asphalt Pavements, Reclaimed Asphalt Pavement, Recycling, Rutting, Fatigue Cracking, Thermal Cracking

\section{Introduction}

Due to heavy traffic loads and environmental conditions that are not considered in the design of asphalt pavements, more and more asphalt pavements are failing prematurely, as a result overlaying or replacing failing pavements become a necessity. Overlaying a pavement is a simple process, where a new asphalt layer is added, the problem with overlaying is the nature of the asphalt mix materials, which will take the form of the lower layer and most distress will be reflected on it after opening road for traffic (Figure 1). The best solution is to mill the surface of the old pavement to remove the affected part of the pavement (Figure 2), then the question is what to do with the removed materials, either dump it in landfill or reuse it as construction materials, hence the use of reclaimed asphalt pavement (RAP) came into the picture with a promise of many

* Corresponding author

E-mail: ahmed.abuabdo@aurak.ac.ae

(C) 2016 International Association for Sharing Knowledge and Sustainability

DOI: $10.5383 /$ ijtee.12.01.008 economic and environmental benefits. Currently, almost all RAP is recycled back into pavements [1], for example it is estimated that a 30,000 ton pile of RAP with an average $6 \%$ liquid asphalt binder content is the equivalent of about 28,200 tons of clean aggregate plus 10,000 Barrels of liquid asphalt, which could replace virgin materials [2].

The most recycled materials in the United States is asphalt pavement materials. Over $80 \%$ of asphalt pavement materials milled from roadways is reused. It can be mixed into new pavement or used as a subbase or fill material. In 2012, American asphalt plants used an estimated 68.3 million tons of reclaimed asphalt pavement to produce new asphalt [3]. RAP was first used in 1973 with $3 \%$ allowed to replace virgin materials in an asphalt mix, and since then and due to the increase of cost of asphalt binder, higher percentages were allowed, reaching nowadays 20 to $30 \%$ and even 50\% [4]. The asphalt industry is considered number-one recycler and in 2012 
almost all (98\%) contractors in the United States reported using RAP with estimated savings of $\$ 2.04$ billion at $\$ 600$ per ton for asphalt binder [4]. Even though, using RAP proves to have economic and environmental advantages, it is still unclear the level of interaction between RAP and virgin asphalt mixes, and it is essential to evaluate the effects of

RAP on the performance of asphalt pavements before implementing and allowing such high percentages in new asphalt pavements.

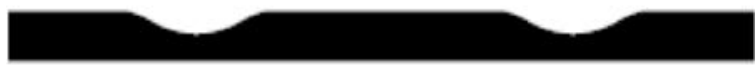

\section{Original Roadbed}

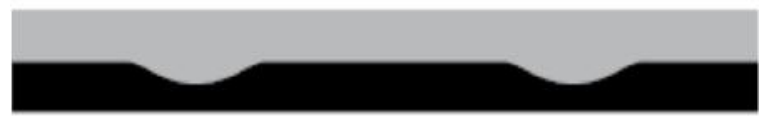

\section{After Overlay}

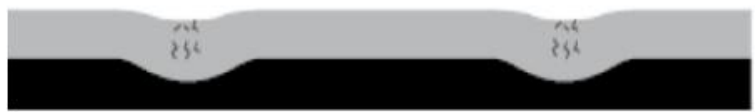

\section{After Traffic}

Figure 1 Overlaying over Distressed Asphalt Pavement (After [2])

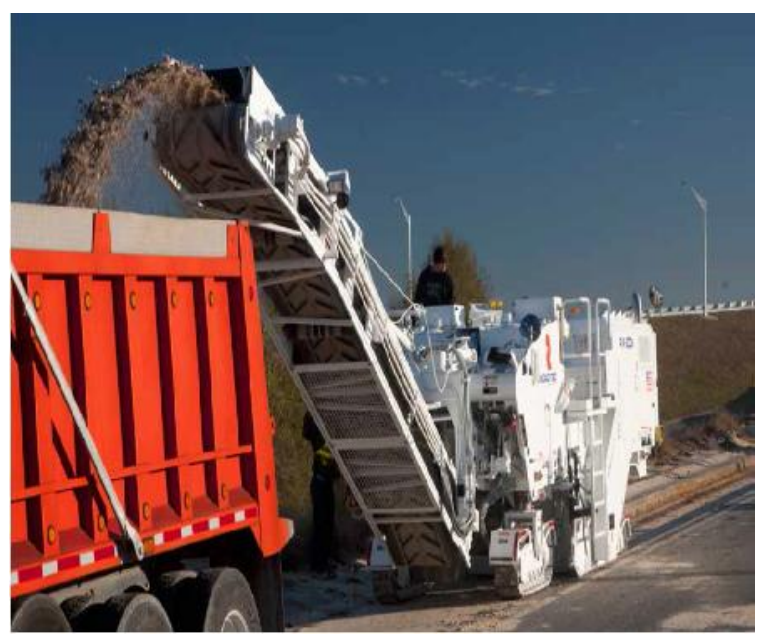

Figure 2 Milling of Asphalt Pavements (Courtesy of Roadtec)

\section{Scope}

The Department of Public Works and Services at Ras Al Khaimah has started experimenting with RAP (e.g. Kadra-
Shawka Road) with expectations that it is eco-friendly, reduces environment pollution and would enhance the durability of newly constructed roads [5]. However, the impact of using RAP should be investigated, especially the amount to be added. Thus, a full experimental study to evaluate the performance of such mixes, especially in rutting and fatigue cracking has been initiated. As a first step in this study, a full literature review related to RAP was conducted. This paper presents the findings of the literature review and its implication on this research project.

\section{Reclaimed Asphalt Pavement Materials in Pavement Base or Subbase Layers}

Since most agencies do not allow high percentages of RAP in surface layer (hot mix asphalt) and to avoid issues with storage of RAP for an extended period of time, many studies were conducted on the use of RAP as a stabilization material in pavement Base and/or Subbase layers. Hoppe et al. [6] investigated the use of RAP for road base and subbase applications. Their study showed that the usage of RAP in road base and subbase materials was feasible and no major environmental concerns appeared to be related to using unbound RAP without chemical stabilization agents. Furthermore, a study by Locander [7] found that using RAP as an unbound aggregate base course was a suitable alternative approach, where the stiffness strength properties tests showed the RAP had stiffness strength higher than an unbound traditional used base and had a slightly higher permeability. McGarrah [8] argued that when the RAP percentage increased over $50 \%$, the properties of the blend could have severe effects. Further evaluation should be conducted to better determine a maximum percentage of RAP, and it was better to maintain RAP percentage at $35 \%$ for base and sub base applications. Ansori and Radam [9] reported a huge drop in California Bearing Ratio (CBR) Test with the increase of RAP (Figure 4). CBR is the main design criterion when designing base and sub base layer thicknesses, and based on their findings, RAP could be used with no more than $3 \%$ for base courses, $9 \%$ for subbase courses, and $10 \%$ courses without asphalt coverings or shoulder.

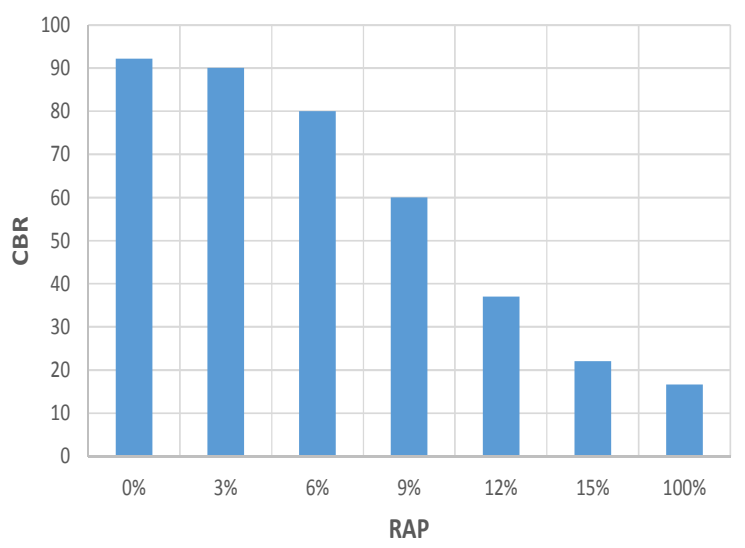

Figure 3 CBR Values based on the RAP Percentage in Each Combination (after [9]) 


\section{Reclaimed Asphalt Pavement Materials in Pavement Surface Layer}

The most use of RAP is in hot asphalt mix. It involves mixing RAP with new or "virgin" aggregates, neat asphalt binder, and/or recycling agents in a central hot mix plant to produce a recycled mix. The percentage of RAP permitted in a recycled mix varies by agency as well as guidelines as to where the recycled mix can be used in the pavement structure. Some agencies allow $15 \%$ or less RAP while others permit larger amounts of RAP. Higher RAP percentages require modifications in mix design and binder selection. Suggested guidelines relative to RAP content in a recycled mix are as follows: 15\% RAP or less: binder grade is the same as that used in a virgin mix; $15-25 \%$ RAP: binder grade should be one grade lower on both high and low temperature end, i.e. PG 5822 rather than PG 64-16; higher than 25\% RAP: perform tests to determine the percentage of RAP and ensure the quality of the blend [10].

RAP is mixed with aggregate and asphalt binder to yield a recycled mix and there are different ways to complete the process and it is governed by the configuration of the hot mix plant. RAP is added directly to the mixer in a drum mix plant (Figures 4-a, 4-b, and 4-c). The inlet at which RAP is added to the drum mixer relies on the mixer type (parallel flow versus counter flow versus double barrel) and whether or not a separate coater is included in the drum mix operation [2]. Once the recycled mix has been produced, it is either delivered to the construction site to be placed and compacted or stored in silos for future delivery. No special techniques are needed to handle recycled mix. However, special care and consideration should be employed when compaction of the recycled mix, since the recycled mix temperature will be slightly lower than the conventional mix, to avoid overheating the mix at the plant [11].

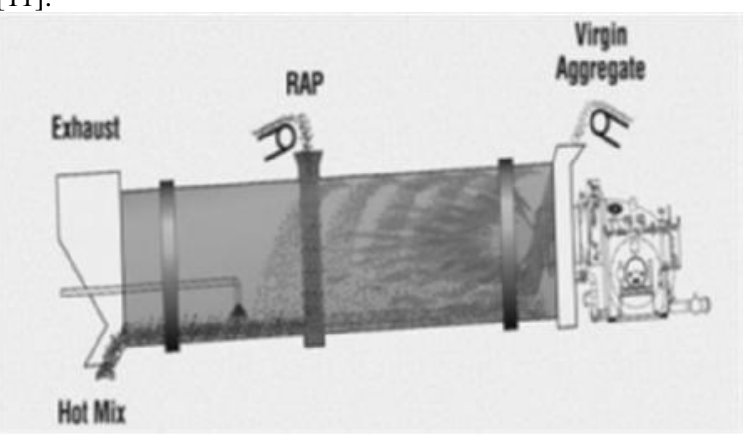

(a) Parallel Flow Drum Mixer

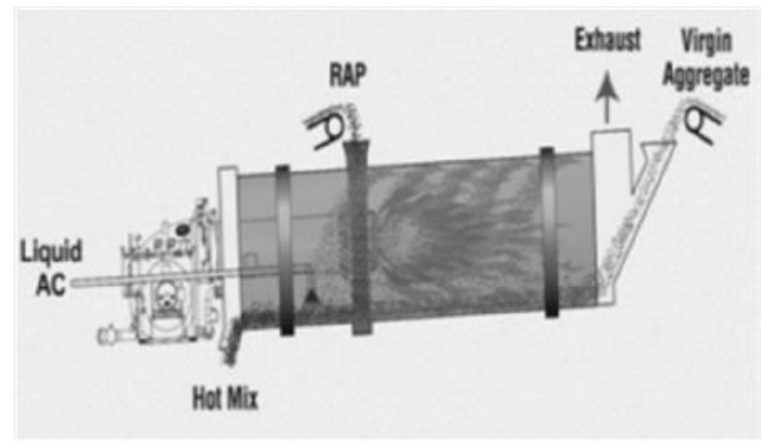

(b) Counter Flow Drum Mixer

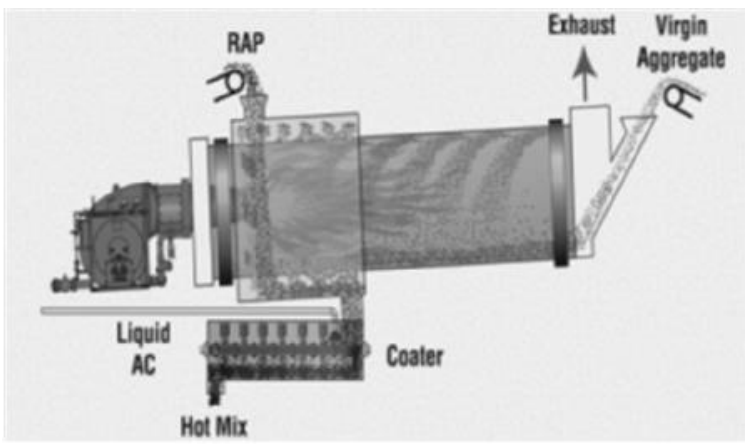

(c) Double RAP Dryer with Coater

(Figure 3 Different Types of Asphalt Mixing Drums (Courtesy of Astec, Inc.)

\section{Performance of Asphalt Mixes with Reclaimed Asphalt Pavement Materials}

The main question that many studies tried to answer is how the addition of RAP to virgin mixes affect their performance. Will the combined mix perform better, the same, or less than without RAP? What is the optimum amount of RAP to be added? RAP is essentially aged asphalt mix, which is stiffer and less ductile, giving the combined mix more strength but less flexibility, which may cause cracks to appear quicker than a conventional mix. Many agencies experimented with different percentages of RAP in hope to answer the above mentioned questions.

A study on Michigan and the Missouri samples showed that mixes containing RAP had similar stiffness to virgin mixes. However, results of the shear tester demonstrated the stiffening effect of RAP materials on the mix properties. The increased stiffness may improve permanent deformation (rutting) resistance of the combined mix but it could increase the potential for fatigue and thermal cracking [12].

In the following sections, the effect of RAP on the performance of asphalt mixes is discussed.

\section{Permanent Deformation (Rutting)}

Rutting is one of the main distresses in asphalt pavements, it is defined as the depression under the wheel path and can be clearly observed after a rainfall. Rutting is one of the essential parameter in design and evaluation of asphalt pavements, and it occurs mainly in the first 5-7 years of an asphalt pavement life. A study by Pradyumna et al. [13] evaluated rutting resistance on mixes with $20 \%$ RAP, they utilized a Wheel Tracking Device (WTD) with an application of 20,000 passes of the rolling wheel at $45{ }^{\circ} \mathrm{C}$. The result showed that mixes with RAP exhibited lower rutting depths than virgin mixes. Thus, the addition of RAP improved the rutting resistance of an asphalt mix, since mixes with RAP become stronger and stiffer when compared to virgin mixes leading to better resistance to permanent deformation. 
Hussain and Yanjun [14] experimented with Marshall Method. They concluded that Marshall Stability increased with the increase in RAP with good linearity, reaching twice the stability for mixes with $100 \%$ RAP when compared to the control mix. Furthermore, they argued that using RAP in design even up to $30 \%$ will help in preserving natural resources, reduction in costs, and performance improvement.

Abu El-Maaty and El-Moher [15] suggested that mixes with RAP, especially at $50 \%$ to $100 \%$, when properly designed showed better performance compared to those of virgin mixes. Mixes with RAP showed improvement in the indirect tensile strength where the highest value was achieved at $50 \%$ RAP content exhibited a $106 \%$ increase when compared to control mixes. Additionally, the increase in RAP content enhanced the resilient modulus, absorbed energy, and rutting (Figure 5) by about 216\%, 194\% and 70\% respectively.

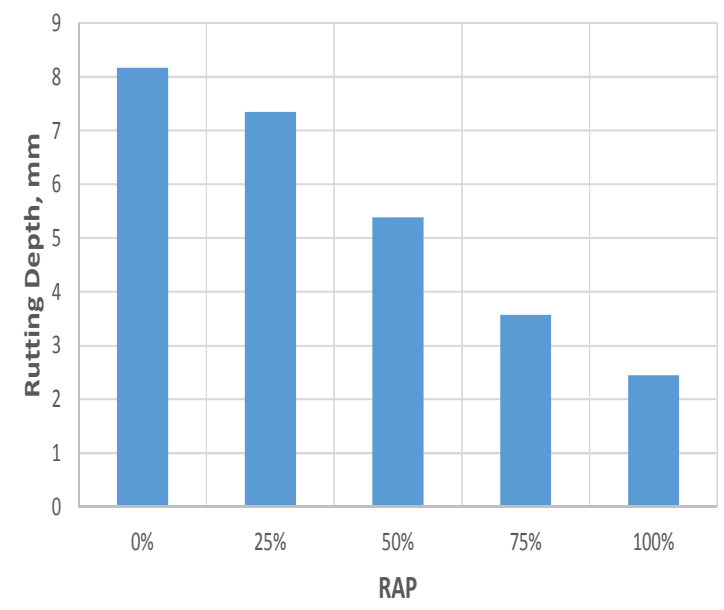

Figure 4 Rutting Depths of Mixes with Different RAP Percentages (After [15])

\section{Fatigue Cracking}

Fatigue cracking starts from the bottom of the asphalt layer where the tensile stress and strain is high due to repeated loading and it propagates to the surface layer as one or few longitudinal parallel cracks. These cracks increase and connect with other cracks and form a net, which is called alligator cracking. Tabakovic' et al. [16] conducted laboratory tests on asphalt mixes with RAP and results showed an improvement in all mechanical properties, especially mixes with $30 \%$ RAP performed better than control mixes with no RAP in Fatigue tests. In particular, it was found that the mixes containing up to $30 \%$ RAP, displayed improved fatigue resistance relative to the control mix manufactured from virgin materials.

Ajideh et al. [17] investigated asphalt mixes that contained $50 \%$ RAP. They developed scanning laser detection technology, which could scan tested samples and capable of capturing cracks and exhibits a strong correlation with the results from the conventional and energy-based approaches.
Based on their results, they argued that the 50\% RAP mix could be environmental and economic beneficial and exhibit good performance. Pradyumna et al. [13] observed an improvement in the fatigue life with increase of RAP content in an asphalt mix. It was found that by adding 20\% RAP, fatigue life increased by $67.2 \%$ compared to a virgin mix.

On the other hand, a study by Sunil et al. [18] on fatigue life of mixes with different RAP contents found that the increase of RAP reduced fatigue resistance of these mixes. Fatigue tests were conducted at three stress ratios $(60 \%, 70 \%$ and $80 \%$ ), as shown in Figure 6, the number of cycle to failure reduced with increase of the percentages of RAP but still met the design requirements.

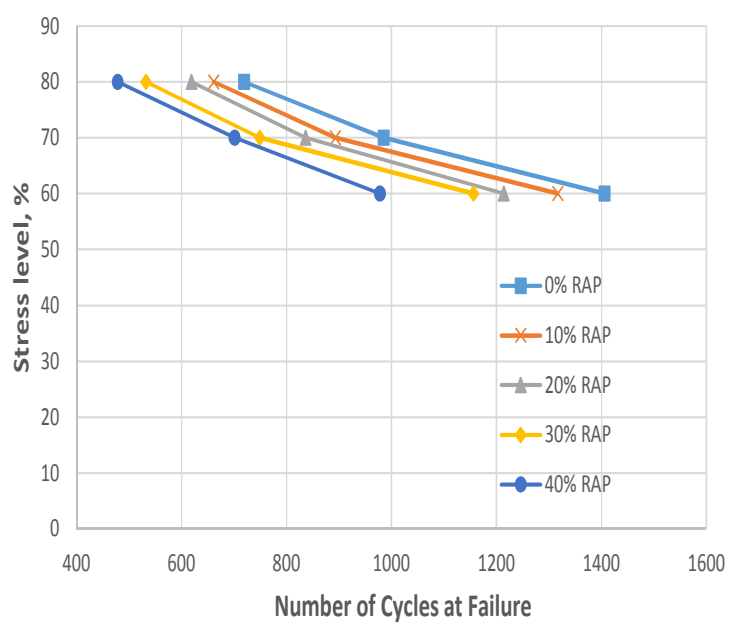

Figure 5 Fatigue Cycle Test Results for Different Percentages of RAP (After [26])

\section{Thermal Cracking}

Thermal cracking defined as an isolated crack that runs perpendicular to traffic, it occurs at high load combined with cold temperatures at which the asphalt pavement becomes very stiff and brittle and breaks. Low temperature testing of laboratory mixes with up to 55\% RAP, found that the creep stiffness measured by the Indirect Tensile Test (IDT) increased along with RAP content and that the addition of RAP significantly reduced crack resistance. Also, the increase of RAP in mixes lowered the fracture energy measured by the Semi-Circular Bend Fracture Test (SCBT). Thus, the increase in RAP content led to a drop in fracture resistance at cold temperatures [19].Taha et al. [20] explored thermal cracking resistance of mixes containing RAP. It was found that at lower temperatures, the mix containing a lower RAP content was stiffer resulting in higher creep compliance and indirect tensile strength values. In a similar study, Solanki et al. [21] argued that mixes with RAP showed a slight increases in IDT strengths but were not enough to cause larger increases in thermal stress. Results from SCBT Tests showed that with the increase of RAP, the fracture energy decreased and the fracture toughness increased in these mixes as illustrated in Figure 7. Furthermore, all tested mixes did not meet the fracture toughness or energy minimum recommended levels. 


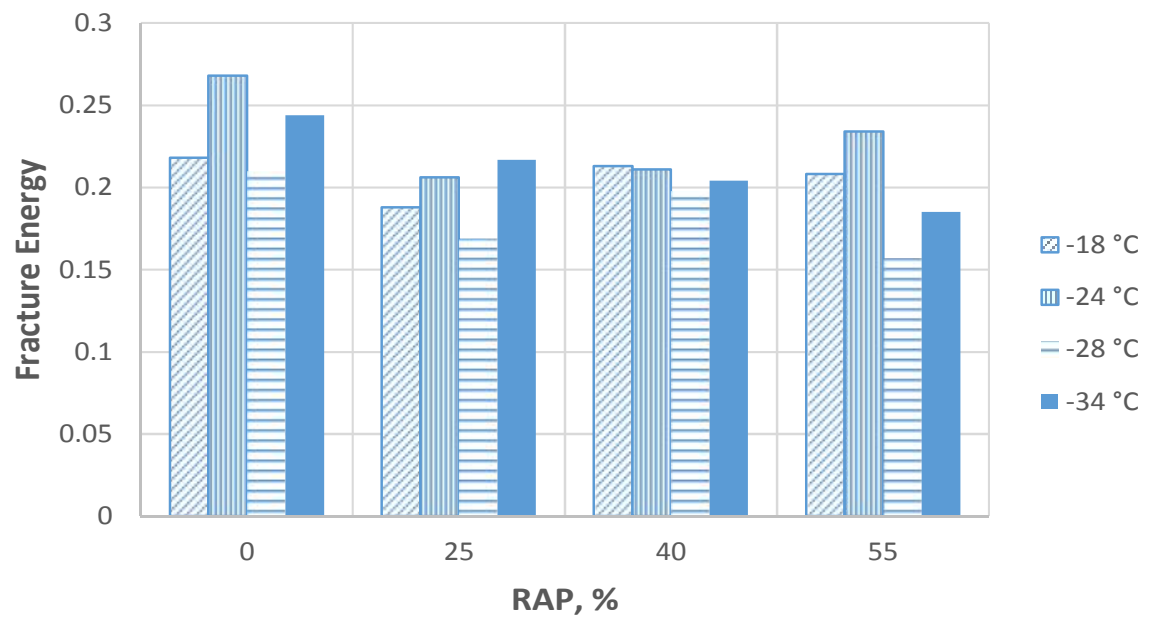

Figure 6 SCBT Tests Results for Different Percentages of RAP (After [21])

\section{Summary and Recommendations}

With the increase of costs of pavement materials and calls to reserve natural resources, more agencies are incorporating reclaimed asphalt pavement materials (RAP) in new pavement designs. This process has been used decades ago, but with lower contents. Nowadays, higher percentages (e.g. $>50 \%$ ) are being adopted to save money and natural resources.

Permanent deformation (rutting), fatigue cracks, and thermal cracks are the main distresses that affect the performance of asphalt mixes. Many studies had been conducted to evaluate the effect of RAP on the performance of asphalt pavements and showed that RAP increases the stiffness of asphalt mixes, due to the aged asphalt binder. Resulting in an improvement of rutting resistance and better performance at high temperature. On the other hand, results were not consistent when it came to fatigue and thermal cracking. Few studies argued that there were no effects of RAP on these distresses, where other studies showed a reduction in fatigue and thermal cracking resistance leading to a poor performance of these mixes.

Recently, the Department of Public Works and Services at Ras Al Khaimah started adopting RAP mixes in ongoing projects (Kadra-Shawka Road) with no clear guidelines. Due to the hot weather conditions in Ras Al Khaimah, it is speculated that these roads would perform better than traditionally built roads. However, fatigue cracking, which might be a big concern is not addressed. It is recommended that before implementing such project to conduct a methodological experimental program to evaluate local materials, develop guidelines for use of RAP, and most importantly to pinpoint the correct RAP percentage for such projects in Ras Al Khaimah. Thus, this study was initiated. In the meantime, RAP usage should be limited to base and subbase layers.

\section{References}

[1] Okafor, F.O. (2010). Performance of Recycled Asphalt Pavement as Coarse Aggregate in Concrete. Leonardo
Electronic Journal of Practices and Technologies, 17, pp. 47-58.

[2] Brock, J. D. and J.L. Richmond (2006). Milling and Recycling. ASTEC Inc., Technical Paper T-127, Chattanooga TN, USA.

[3] FHWA (2012). User Guidelines for Waste and Byproduct Materials in Pavement Construction. Federal Highway Administration, USA.

[4] Hansen, K.R. and A. Copeland (2013). Annual Asphalt Pavement Industry Survey on Recycled Materials and Warm-Mix Asphalt Usage: 2009-2012. Federal Highway Administration, Final Report 2009-2012, USA.

[5] Shaaban A. (2015). RAK Re-lays Road with Recycled Material. Khaleej Times, Filed on March 24, 2015.

[6] Hoppe, E.J., D.S. Lane, G.M. Fitch, and S. Shetty (2015). Feasibility of Reclaimed Asphalt Pavement (RAP) Use as Road Base and Subbase Material. Virginia Center for Transportation Innovation and Research, Final Report VCTIR 15-R6, USA.

[7] Locander, R. (2009). Analysis of Using Reclaimed Asphalt Pavement (RAP) as a Base Course Material. Colorado Department of Transportation Materials/Geotechnical Branch, Report CDOT-2009-5, USA.

[8] McGarrah, E.J. (2007). Evaluation of Current Practices of Reclaimed Asphalt Pavement/Virgin Aggregate as Base Course Material. Washington State Department of Transportation, Report WA-RD 713.1, USA.

[9] Ansori, M. and I. F. Radam (2015). The Use of Reclaimed Asphalt Pavement as a Foundation for Pavements Based On the Indonesian National Standard. International Journal of Engineering Research and Applications, 15 (2), pp.14-18.

[10] McDaniel, R.S. and A. Shah (2003). Use of Reclaimed Asphalt Pavement (RAP) Under Superpave Specifications. Journal of the Association of Asphalt Paving Technologists, 72, pp. 226-252.

[11] Santucci, L. (2007). Recycling Asphalt Pavements - A Strategy Revised. Technology Transfer Program, and Pavement Specialist, Pavement Research Center, Institute of Transportation Studies, 8, USA.

[12] McDaniel, R.S. and A. Shah (2003). Use of Reclaimed Asphalt Pavement (RAP) Under SuperPave 
Specifications. Journal of the Association of Asphalt Paving Technologists, 72, pp. 226-252.

[13] Pradyumna, T.A., A. Mittal, and P.K. Jain (2013). Characterization of Reclaimed Asphalt Pavement (RAP) for Use in Bituminous Road Construction. Procedia Social and Behavioral Sciences, 104, pp. 1149-1157.

[14] Hussain, A. and Q. Yanjun (2012). Laboratory Evaluation of Asphalt Mixtures Containing Various Percentages of Reclaimed Asphalt Pavement. Asian Journal of Natural \& Applied Sciences, 1(2), pp. 156163.

[15] Abu El-Maaty, A.E. and A.E. El-Moher (2015). Evaluation of Hot Asphalt Mixtures Containing Reclaimed Asphalt Pavements. International Journal of Engineering and Advanced Technology (IJEAT), 4(4), pp. 197-206.

[16] Tabakovic', A., A. Gibney, C. McNally, and M.D. Gilchrist (2010). Influence of Recycled Asphalt Pavement on Fatigue Performance of Asphalt Concrete Base Courses. Journal of Materials in Civil Engineering, 22(6), pp. 643-650.

[17] Ajideh, H., H. Bahia, S. Carnalla, and J. Earthman (2013). Evaluation of Fatigue Life of Asphalt Mixture with High RAP Content Utilizing Innovative Scanning Method. Airfield and Highway Pavement 2013, pp. 1112-1121.

[18] Sunil, S., K.M. Mallesh, and T. Chandrasekaraiah (2014). Experimental Investigation on the performance of Bituminous Mixes with Reclaimed Asphalt Pavement (RAP) Materials (Case Study Tumkur to ChitradurgaNH4. International Journal of Research in Engineering and Technology (IJRET), 3(6), pp. 297-303.

[19] Johnson, E., M. Watson, R. Olson, K. Hoon Moon, M. Turos, and M. Marasteanu (2013). Recycled Asphalt Pavement: Study of High-RAP Asphalt Mixtures on Minnesota County Roads, Report MN/RC 2013-15, USA.

[20] Taha, R., A. 1-Harthy, K. Al-Shamsi, and M. Al-Zubeidi (2002). Cement Stabilization of Reclaimed Asphalt Pavement Aggregate for Road Bases and Subbases. Journal of Materials in Civil Engineering, 14(3), pp 239-245.

[21] Solanki, P., M. Zaman, D. Adje, and Z. Hossain (2015). Effect of Recycled Asphalt Pavement on Thermal Cracking Resistance of Hot-Mix Asphalt. International Journal Geomechanics, 15(5), pp. 145306:1-6. 